\title{
Hepatic hypertrophy and hemodynamics of portal venous flow after percutaneous transhepatic portal embolization
}

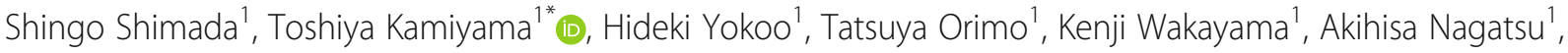 \\ Tatsuhiko Kakisaka ${ }^{2}$, Hirofumi Kamachi ${ }^{1}$, Daisuke $\mathrm{Abo}^{3}$, Yusuke Sakuhara ${ }^{3}$ and Akinobu Taketomi ${ }^{1}$
}

\begin{abstract}
Background: Percutaneous transhepatic portal embolization (PTPE) is useful for safe major hepatectomy. This study investigated the correlation between hepatic hypertrophy and hemodynamics of portal venous flow by ultrasound sonography after PTPE.

Methods: We analyzed 58 patients with PTPE, excluding those who underwent recanalization $(n=10)$. Using CT volumetry results 2 weeks after PTPE, the patients were stratified into a considerable hypertrophy group $(\mathrm{CH} ; n=15)$ with an increase rate of remnant liver volume (IR-RLV) $\geq 40 \%$ and a minimal hypertrophy group $(\mathrm{MH} ; n=33)$ with an IR-RLV $<40 \%$. We investigated the hemodynamics of portal venous flow after PTPE and the favorable factors for hepatic hypertrophy.

Results: Univariate and multivariate analysis identified the indocyanine green retention rate at 15 min (ICGR15) and increase rate of portal venous flow volume (IR-pFV) at the non-embolized lobe on day 3 after PTPE as independent favorable factors of IR-RLV. Patients with IR-pFV on day 3 after PTPE $\geq 100 \%$ and ICGR15 $\leq 15 \%(n=13)$ exhibited significantly increased IR-RLV compared with others $(n=35)$.
\end{abstract}

Conclusions: Cases with high IR-pFV on day 3 after PTPE exhibited better hepatic hypertrophy. Preserved liver function and increased portal venous flow on day 3 were important.

Keywords: Portal venous flow, Hepatic hypertrophy, Percutaneous transhepatic portal embolization

\section{Background}

Complete resection of hepatobiliary malignant tumors is the best method to achieve long-term survival $[1,2]$. Major hepatectomy is often required for complete resection, and one of the main causes of unresectability is insufficient remnant liver volume (RLV). Percutaneous transhepatic portal embolization (PTPE) is a useful method for safe major hepatectomy for hepatobiliary malignant tumors [3]. Although PTPE promotes hypertrophy in the non-embolized liver and increases the future remnant liver function and volume [4], some patients exhibit insufficient hypertrophy at the non-embolized liver

\footnotetext{
* Correspondence: t-kamiya@med.hokudai.ac.jp

${ }^{1}$ Department of Gastroenterological Surgery I, Hokkaido University Graduate School of Medicine, Kita15-Nishi7, Kita-Ku, Sapporo, Hokkaido 060-8638, Japan

Full list of author information is available at the end of the article
}

with between 2.8 and $4.5 \%$ of patients unable to undergo surgery after PTPE due to insufficient hypertrophy $[5,6]$. Furthermore, the degree of hypertrophy and growth rate of the remnant liver after portal vein embolization (PVE) are favorable predictors of post-hepatectomy liver failure [7]. Thus, increased hypertrophy after PTPE is a crucial factor.

Although it was previously reported that hepatic injury (fibrosis or cirrhosis) was an unfavorable factor for hepatic hypertrophy after PTPE [3], favorable factors for hypertrophy after PTPE remain elusive. In addition, the hemodynamics of portal venous flow after PTPE has been not investigated in detail. In this study, we examined the favorable factors for remnant liver hypertrophy and hemodynamics of portal venous flow volume (pFV) after PTPE at the non-embolized lobe by ultrasound sonography (US).

(c) The Author(s). 2019 Open Access This article is distributed under the terms of the Creative Commons Attribution 4.0 International License (http://creativecommons.org/licenses/by/4.0/), which permits unrestricted use, distribution, and reproduction in any medium, provided you give appropriate credit to the original author(s) and the source, provide a link to the Creative Commons license, and indicate if changes were made. The Creative Commons Public Domain Dedication waiver (http://creativecommons.org/publicdomain/zero/1.0/) applies to the data made available in this article, unless otherwise stated. 


\section{Methods}

\section{Patients}

Between January 2004 and November 2015, 58 patients underwent PTPE for hepatectomy at the Gastroenterological Surgery I unit of Hokkaido University Hospital in Sapporo, Japan. The entire liver volume, liver resection volume, and tumor volume were calculated from contrast-enhanced computed tomography (CT) data by 3D workstations (Virtual Place Lexus; Medical Imaging Laboratory, AZE, Tokyo, Japan, and Synapse Vincent, Fujifilm Medical Co., Ltd., Tokyo, Japan). PTPE was performed in patients with an effective liver resection rate $>60 \%$ according to the formula [(liver resection volume - tumor volume) / (whole liver volume - tumor volume) $\times 100$ [8]. The diagnoses and surgical data of the patients are presented in Table 1 . We performed bile duct drainage (mainly nasobiliary drainage) before in cases which T-bil $\geq 2.0 \mathrm{mg} / \mathrm{dL}$. PTPE were performed for the cases which $\mathrm{T}$-bil $<2.0 \mathrm{mg} / \mathrm{dL}$.

\section{PTPE}

The PTPE method was previously reported [9] and is briefly described here. Most patients underwent an ipsilateral approach, but the contralateral approach was used when the ipsilateral approach was judged to be unsuitable by interventional radiologists. After the administration of local anesthesia, the intrahepatic portal vein was punctured with an 18-gauge needle (Needle for Ultrasonically Guided Puncture; Create Medic Co., Yokohama, Japan) under US guidance. A 5.5-French sheath introducer (Introducer Set; Medikit Co., Tokyo, Japan) was inserted into the portal vein with a guidewire. Direct portography was performed to evaluate the anatomy and measurement of portal venous pressure (PVP)

Table 1 Patient diagnoses and operative procedures

\begin{tabular}{ll}
\hline Diagnosis & \\
Hepatocellular carcinoma & 13 \\
Intrahepatic cholangiocarcinoma & 4 \\
Bile duct cancer & 34 \\
Metastatic liver cancer & 2 \\
Gallbladder cancer & 5 \\
Operative procedure & \\
Right hepatectomy & 38 \\
Extended right hepatectomy & 6 \\
Right trisegmentectomy & 3 \\
Left hepatectomy & 1 \\
Left trisegmentectomy & 4 \\
Right hepatectomy with pancreatoduodenectomy & 3 \\
Unresectable cases & 3 \\
\hline
\end{tabular}

directly. Next, selective portography was performed with a balloon occlusion catheter (Selecon MP Catheter II; Terumo Co., Tokyo, Japan). The embolic material was absolute ethanol. The method of ethanol injection was previously reported. ${ }^{9}$ After repeat embolization until the resolution of hepatic parenchymal enhancement, direct portography was performed to confirm the PTPE result. Then, we directly measured PVP at the non-embolized lobe. Finally, the 5.5-French sheath was extracted by packing the puncture tract with a gelatin sponge torpedo (Spongel; Astellas Pharma Co., Tokyo, Japan).

\section{Assessments}

The patients' liver volumes and RLVs were semiautomatically measured by 3D workstations using contrast-enhanced CT imaging data before PTPE and 1 and 2 weeks after PTPE. pFV was measured thrice by pulsed wave Doppler US (Toshiba SSA-700A (Aplio50), Toshiba Medical Systems Co., Ltd., Tokyo, Japan, and LOGIQ P6 BT11, GE Healthcare JAPAN Co., Ltd., Tokyo, Japan) on days $1,3,5$, and 7 after PTPE. We calculated pFV as following, $\mathrm{pFV}=$ portal velocity (pulsed wave Doppler US $) \times \pi r(r=\text { radius of portal vein })^{2}$. We averaged the 3 readings on each day to calculate the pFV. We measured the pFV of the umbilical portion for right-side hepatectomy, the anterior branch for left hepatectomy, and the posterior branch for left trisegmentectomy.

Patients were stratified into a considerable hypertrophy group $(\mathrm{CH} ; n=15)$ and a minimal hypertrophy group $(\mathrm{MH} ; n=33)$ based on the increase rate of RLV (IR-RLV), i.e., $\geq 40 \%$ versus $<40 \%$, respectively, according to the formula [(RLV at 2 weeks after PTPE - RLV before PTPE) / RLV before PTPE] $\times 100$. We investigated the favorable factors for hepatic hypertrophy and hemodynamics of pFV after PTPE. Using the formula [(pFV after PTPE - pFV before PTPE) / pFV before PTPE] $\times 100$, we evaluated the increase rate of $\mathrm{pFV}$ (IR-pFV) at the non-embolized lobe on days 1, 3, 5, and 7 after PTPE by US; the portal venous pressure (PVP) before and after PTPE; patients' age and sex; hemoglobin, white blood cell, C-reactive protein, aspartate aminotransferase, alanine aminotransferase, platelet, cholinesterase, albumin, total bilirubin (T-bil), and A1c glycated hemoglobin levels; hepatitis B surface antigen; hepatitis $C$ virus antibody; the indocyanine green retention rate at $15 \mathrm{~min}$ (ICGR15); pathological liver fibrosis; and the receptor index [uptake ratio of the liver to that of the liver plus heart at 15 min of technetium $99 \mathrm{~m}$ diethylenetriaminepentaacetic acid-galactosyl-human serum albumin scintigraphy (LHL15)]. Patients who had portal venous recanalization after PTPE were excluded $(n=10,17.2 \%)$.

We performed the assessment of hypertrophy by CT at 2 weeks because most cases $(86 \%, 50 / 58)$ underwent 
hepatectomy with satisfaction for our criteria at 2 weeks after PTPE.

This study was approved by the Hokkaido University Hospital Voluntary Clinical Study Committee and was performed according to Helsinki Declaration guidelines.

\section{Statistical analysis}

Values are expressed as the mean \pm standard deviation. Univariate analyses were performed using Student's $t$-test for continuous variables and the chi-square test for non-continuous variables. Multivariate analyses were performed using logistic regression model analyses. Pearson's correlation coefficients were used to analyze the correlation between the IR-pFV at the non-embolized lobe by US and the IR-RLV. A $P$-value of $<0.05$ was considered significant. Statistical analyses were performed using JMP Pro 12.0.1 for Windows (SAS Institute Inc., NC, USA).

\section{Results}

\section{Perioperative data of patients}

Patient perioperative data are provided in Table 1. The diagnoses in our study cohort were hepatocellular carcinoma $(n=13)$, intrahepatic cholangiocarcinoma $(n=4)$, bile duct cancer $(n=34)$, metastatic liver cancer $(n=2)$, and gallbladder cancer $(n=5)$. The operative procedures were right hepatectomy $(n=38)$, extended right hepatectomy $(n=6)$, right trisegmentectomy $(n=3)$, left hepatectomy $(n=1)$, left trisegmentectomy $(n=4)$, and right hepatectomy with pancreatoduodenectomy $(n=3)$. Three tumors were unresectable $(n=3)$. The mean waiting time from PTPE to surgery was 26 days (15-96). Table 2 reports total hepatic volume, RLV, effective liver resection rate before and after PTPE. The mean RLVs before and after PTPE were $438.6 \pm 106 \mathrm{~mL}$ and $558.8 \pm 99.9 \mathrm{~mL}$, respectively $(P<0.01)$. The median IR-RLV was $30.5 \%$. Only one complication occurred, namely, hemobilia (1.7\%). No patient exhibited transient thrombocytopenia (defined as a platelet count less than $50 \times 10^{3}$ cells $/ \mu \mathrm{L}$ ). All recanalization rates after PTPE were $17.2 \%$. However, all cases had recanalization beyond the third portal branches. No cases exhibited recanalization at second or first portal branches. Two cases of all 10 recanalization cases needed additional PVE, that is 1 case was performed PTPE, 1 case was performed TIPE. Recanalization cases showed that the mean RLVs before and after PTPE were $304.3 \pm 23 \mathrm{~mL}$ and $397.8 \pm 53.8 \mathrm{~mL}$,

Table 2 Liver volume and resection rates before and after PTPE

\begin{tabular}{llll}
\hline & $\begin{array}{l}\text { Total liver } \\
\text { volume }(\mathrm{ml})\end{array}$ & $\begin{array}{l}\text { Remnant liver } \\
\text { volume }(\mathrm{ml})\end{array}$ & $\begin{array}{l}\text { Effective liver } \\
\text { resection rate (\%) }\end{array}$ \\
\hline Before PTPE & $1383.4 \pm 395.5$ & $438.6 \pm 106$ & $63.8 \pm 7.4$ \\
$\begin{array}{l}2 \text { weeks after } \\
\text { PTPE }\end{array}$ & $1394.9 \pm 459.2$ & $558.8 \pm 99.9$ & $54.8 \pm 7.3$ \\
\hline
\end{tabular}

PTPE percutaneous transhepatic portal embolization respectively $(P<0.01)$. The median IR-RLV was $26.9 \%$. No cases exhibited post-hepatectomy liver failure. Regarding 8 cases could not achieve our criteria for hepatectomy at 2 weeks after PVE, 2 cases achieved our criteria for hepatectomy at 4 weeks after PVE, 3 cases at 5 weeks, 1 case at 6 weeks, 1 case at 7 weeks, and 1 case at 8 weeks.

\section{Correlation between IR-RLV and high IR-pFV cases}

We evaluated the IR-RLV of the cases with regard to an IR-pFV greater than $100 \%$ on days $1,3,5$, and 7 after PTPE using ROC (receiver operating characteristics) curves to determine the cut-off values for IR-RLV. The values were $29.2 \%$ (area under the curve $[$ AUC] $=0.5297$, sensitivity $=59.1 \%$, specificity $=57.7 \%), 37.3 \% \quad($ AUC $=$ 0.6746 , sensitivity $=52.4 \%, \quad$ specificity $=74.1 \%), \quad 42.4 \%$ $($ AUC $=0.6974, \quad$ sensitivity $=47.8 \%, \quad$ specificity $=96.0 \%)$, and $40.7 \%$ (AUC $=0.5661$, sensitivity $=42.9 \%$, specificity $=85.0 \%)$, respectively.

\section{Clinicopathological characteristics in the $\mathrm{CH}$ and $\mathrm{MH}$ groups}

The patients were then classified into two groups, the $\mathrm{CH}$ and $\mathrm{MH}$ groups, based on an IR-RLV cut-off value of $40 \%$ from the above results.

The clinicopathological characteristics of the $\mathrm{CH}$ and $\mathrm{MH}$ groups are provided in Table 3. The following variables were significantly different between these 2 groups: white blood cell count $(4966 \pm 1198 / \mu \mathrm{L}$ vs $6987 \pm 2625 / \mu \mathrm{L}$; $P<0.01)$, T-bil $(0.98 \pm 0.53 \mathrm{mg} / \mathrm{dL}$ vs $1.59 \pm 0.94 \mathrm{mg} / \mathrm{dL}$; $P=0.02)$, ICGR15 $(10.6 \pm 3.7 \%$ vs $16.1 \pm 3.9 \% ; P<0.01)$, PVP after PTPE $\left(18.2 \pm 1.9 \mathrm{cmH}_{2} \mathrm{O}\right.$ vs $20.5 \pm 3.7 \mathrm{cmH}_{2} \mathrm{O}$; $P=0.03)$, IR-pFV by US on day 3 after PTPE $(156 \pm 96 \%$ vs $89 \pm 57 \% ; P<0.01)$, and pathological liver fibrosis $[6.7 \%$ $(1 / 15)$ vs $42.4 \%(14 / 33) ; P=0.01]$.

Multivariate analysis with logistic regression revealed that ICGR15 (odds ratio $0.5836,95 \%$ confidence interval: $0.3432-0.9922, P=0.04)$ and IR-pFV by US on day 3 after PTPE (odds ratio 1.0257, 95\% confidence interval: 1.0018-1.0501, $P=0.03$ ) were independent favorable factors of increased RLV (Table 4). In addition, patients with an ICGR $15 \leq 15 \%$ and an IR-pFV on day 3 after PTPE $\geq 100 \%$ (favorable group, $n=13$ ) exhibited significantly increased IR-RLV compared with the other patients (unfavorable group, $n=35)(51.6 \pm 24.9 \%$ vs $23.1 \pm$ $15.1 \%, P<0.01$ ) (Fig. 1).

Table 5 showed multivariate analysis for factors turned out before PTPE.

Correlation between the IR-pFV at the non-embolized lobe by US and IR-RLV.

In the $\mathrm{CH}$ group, the IR-pFV continued to increase on days 1 and $3(113 \pm 90 \%$ and $156 \pm 96 \%$, respectively). After day 3 , the IR-pFV was largely maintained $(151 \pm 108 \%$ on day 5 and $160 \pm 112 \%$ on day 7). Conversely, in the $\mathrm{MH}$ group, the IR-pFV generally remained unchanged after day 
Table 3 Clinicopathological characteristics in the considerable hypertrophy and minimal hypertrophy groups by univariate analysis

\begin{tabular}{|c|c|c|c|}
\hline Characteristics & $\mathrm{CH}(n=15)$ & $\mathrm{MH}(n=33)$ & P \\
\hline \multicolumn{4}{|l|}{ Epidemiology } \\
\hline Age & $63 \pm 12$ & $69 \pm 7$ & 0.10 \\
\hline Sex (male/female) & $11 / 4$ & $24 / 9$ & 0.96 \\
\hline HBs-Ag positive (\%) & $1 / 15(6.7 \%)$ & $8 / 33(24 \%)$ & 0.14 \\
\hline HCV-Ab positive (\%) & 0/15 (0\%) & $1 / 33(3 \%)$ & 0.49 \\
\hline \multicolumn{4}{|l|}{ Biochemical factors } \\
\hline 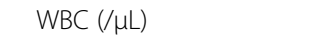 & $4966 \pm 1198$ & $6987 \pm 2625$ & $<0.01$ \\
\hline $\mathrm{Hb}(\mathrm{g} / \mathrm{dL})$ & $12.4 \pm 1.5$ & $13.1 \pm 1.0$ & 0.07 \\
\hline PIt $\left(\times 10^{4} / \mu \mathrm{L}\right)$ & $23.5 \pm 7.9$ & $24.1 \pm 7.5$ & 0.81 \\
\hline CRP (mg/dL) & $0.9 \pm 1.3$ & $0.9 \pm 1.7$ & 0.98 \\
\hline PT (\%) & $92.1 \pm 27.6$ & $94.5 \pm 15.1$ & 0.70 \\
\hline Total bilirubin (mg/dL) & $0.98 \pm 0.53$ & $1.59 \pm 0.94$ & 0.02 \\
\hline AST (IU/L) & $53.7 \pm 27.5$ & $63.4 \pm 57.4$ & 0.53 \\
\hline $\mathrm{ALT}(\mathrm{IU} / \mathrm{L})$ & $67.9 \pm 51.4$ & $84.3 \pm 83.3$ & 0.48 \\
\hline Che (IU/L) & $231.6 \pm 53.6$ & $250.6 \pm 66.9$ & 0.33 \\
\hline Alb $(g / d L)$ & $3.8 \pm 0.5$ & $3.9 \pm 0.4$ & 0.36 \\
\hline $\mathrm{HbA1c}(\%)$ & $5.6 \pm 0.9$ & $5.5 \pm 0.9$ & 0.68 \\
\hline ICGR15 (\%) & $10.6 \pm 3.7$ & $16.1 \pm 3.9$ & $<0.01$ \\
\hline \multicolumn{4}{|l|}{ 99mTc-GSA scintigraphy } \\
\hline LHL15 & $0.914 \pm 0.029$ & $0.915 \pm 0.074$ & 0.95 \\
\hline \multicolumn{4}{|l|}{ Portal pressure } \\
\hline PVP $\left(\mathrm{cmH}_{2} \mathrm{O}\right)$ before PTPE & $13.2 \pm 2.3$ & $14.1 \pm 3.3$ & 0.34 \\
\hline PVP $\left(\mathrm{cmH}_{2} \mathrm{O}\right)$ after PTPE & $18.2 \pm 1.9$ & $20.5 \pm 3.7$ & 0.03 \\
\hline \multicolumn{4}{|l|}{ Portal flow volume } \\
\hline IR-pFV (\%) on day 1 & $112 \pm 90$ & $90 \pm 81$ & 0.40 \\
\hline IR-pFV (\%) on day 3 & $155 \pm 96$ & $90 \pm 59$ & $<0.01$ \\
\hline IR-pFV (\%) on day 5 & $150 \pm 108$ & $111 \pm 96$ & 0.22 \\
\hline IR-pFV (\%) on day 7 & $160 \pm 112$ & $109 \pm 95$ & 0.11 \\
\hline \multicolumn{4}{|l|}{ Histological factors } \\
\hline Fibrosis $(f 2,3,4)(\%)$ & $1 / 15(6.7 \%)$ & 14/33 (42.4\%) & 0.01 \\
\hline
\end{tabular}

$H B s-A g$ hepatitis B surface antigen, $H C V$ - $A b$ hepatitis $C$ virus antibody, WBC white blood cell, $H b$ hemoglobin, Plt platelet, CRP C-reactive protein, PT prothrombin time, AST aspartate aminotransferase, $A L T$ alanine

aminotransferase, Che cholinesterase, Alb albumin, HbA1c A1c glycated hemoglobin, ICGR15 indocyanine green retention test at $15 \mathrm{~min}, 99 \mathrm{mTc}$-GSA technetium $99 \mathrm{~m}$ diethylenetriaminepentaacetic acid-galactosyl-human serum albumin, $L H L 15$, receptor index: uptake ratio of the liver to that of the liver plus heart at $15 \mathrm{~min}$ of technetium $99 \mathrm{~m}$ diethylenetriaminepentaacetic acidgalactosyl-human serum albumin scintigraphy, PVP portal venous pressure, PTPE percutaneous transhepatic portal embolization, IR-pFV increase rate of portal venous flow volume

$1(91 \pm 82 \%$ on day $1,89 \pm 57 \%$ on day $3,112 \pm 97 \%$ on day 5 , and $110 \pm 95 \%$ on day 7) (Fig. 2a). The correlation coefficient between the IR-pFV at the non-embolized lobe by US and the IR-RLV on day 3 was 0.7542 (Fig. 2b, Table 6). The correlation coefficients on days 1,5 , and 7 were 0.4613 , 0.6272 , and 0.5735 , respectively (Table 6).
Table 4 Factors indicative of considerable hypertrophy

\begin{tabular}{llll}
\hline Factors & Odds ratio & $95 \% \mathrm{Cl}$ & $P$ \\
\hline WBC & 0.9989 & $0.9977-1.0001$ & 0.07 \\
Total bilirubin & 1.8378 & $0.3662-9.2247$ & 0.45 \\
ICGR15 & 0.5836 & $0.3432-0.9922$ & 0.04 \\
Fibrosis (f2,3,4) & 0.1305 & $0.0036-4.6704$ & 0.26 \\
PVP after PTPE & 0.7307 & $0.4616-1.1568$ & 0.18 \\
IR-pFV on day3 & 1.0257 & $1.0018-1.0501$ & 0.03 \\
\hline
\end{tabular}

WBC white blood cell, ICGR15 indocyanine green retention test at $15 \mathrm{~min}, P V P$ portal venous pressure, PTPE percutaneous transhepatic portal embolization, $I R-p F V$ increase rate of portal venous flow volume

\section{Discussion}

We investigated the favorable factors for remnant liver hypertrophy and hemodynamics of portal venous flow volume after PTPE. Univariate analysis revealed that the white blood cell count, T-bil, ICGR15, PVP after PTPE, IR-pFV at the non-embolized lobe by US on day 3 after PTPE and pathological liver fibrosis were significant favorable factors for hepatic hypertrophy after PTPE. Multivariate analyses indicated that the ICGR15 and IR-pFV at the non-embolized lobe by US on day 3 after PTPE were independent favorable factors for hepatic hypertrophy after PTPE. We observed a strong positive correlation between the IR-pFV at the non-embolized lobe by US on day 3 after PTPE and the IR-RLV at 2 weeks after PTPE. In addition, we also demonstrated that the pFV after PTPE stabilized from day 3 after PTPE, even in a group of patients exhibiting increased hypertrophy. In this study, patients with an

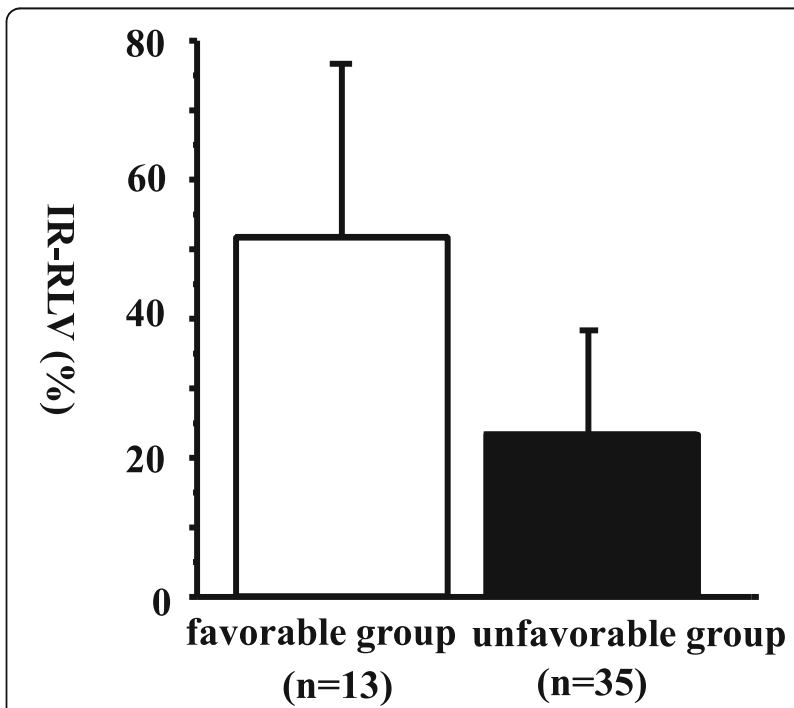

Fig. $1 \mathrm{IR}-\mathrm{RL} V$ according to the presence of favorable conditions, namely an IR-pFV on day $3 \geq 100 \%$ and an ICGR15 $\leq 15 \%$. Patients with an IR-pFV on 3 days after PTPE $\geq 100 \%$ and an ICGR15 $\leq 15 \%$ (favorable group) exhibited a significantly increased IR-RLV compared with other patients (unfavorable group) $(P<0.01)$ 
Table 5 Factors known before PTPE indicative of considerable hypertrophy

\begin{tabular}{llll}
\hline Factors & Odds ratio & $95 \% \mathrm{Cl}$ & $P$ \\
\hline WBC & 0.9994 & $0.9988-1.0001$ & 0.07 \\
Total bilirubin & 0.7503 & $0.1657-3.3977$ & 0.70 \\
ICGR15 & 0.6514 & $0.4736-0.8959$ & $<0.01$ \\
\hline
\end{tabular}

WBC white blood cell, ICGR15 indocyanine green retention test at $15 \mathrm{~min}$

ICGR $15 \leq 15 \%$ and IR-pFV on day 3 after PTPE $\geq 100 \%$ were more likely to exhibit extremely favorable hepatic hypertrophy.

Rous et al. [10] found that ligation of a branch of the portal vein in rabbits resulted in marked atrophy of the parenchyma of the corresponding hepatic lobe with the lobe with uninterrupted portal flow exhibiting regenerative hypertrophy. Subsequently, Makuuchi et al. [11] stated that PVE increased the safety of major hepatectomy for hilar bile duct carcinoma. Kinoshita et al. [12] reported the utility of preoperative PVE before hepatectomy for HCC. Currently, preoperative PVE is widely used for safely performing major hepatectomy for these hepatobiliary malignant tumors [3]. PVE is classified as transileocolic portal embolization (TIPE) or PTPE
Table 6 Correlation between the IR-pFV at the non-embolized lobe by US and the IR-RLV

\begin{tabular}{lc}
\hline Days after PTPE & Correlation coefficients \\
\hline Day 1 & 0.4613 \\
Day 3 & 0.7542 \\
Day 5 & 0.6272 \\
Day 7 & 0.5735 \\
\hline PTPE percutaneous transhepatic portal embolization, $I R-p F V$ increase rate of \\
portal venous flow volume, IR-RLV increase rate of remnant liver volume, US \\
ultrasound sonography
\end{tabular}

according to the specific approach used. Whereas TIPE is performed via laparotomy under general anesthesia, PTPE is performed using a puncture technique with ultrasonic guidance under local anesthesia. Therefore, PTPE is more convenient and is currently more commonly used.

Some reports have demonstrated that the absolute increase in the hypertrophy of the future remnant liver ranged from 28.8 to $43 \%$ [13, 14]. In this study, the value was $30.5 \%$ and thus consistent with previous reports. Regarding procedure-related complications, previous reports reported rates of 12.8 to $14.9 \%[15,16]$; the rate in our study was $1.7 \%$.

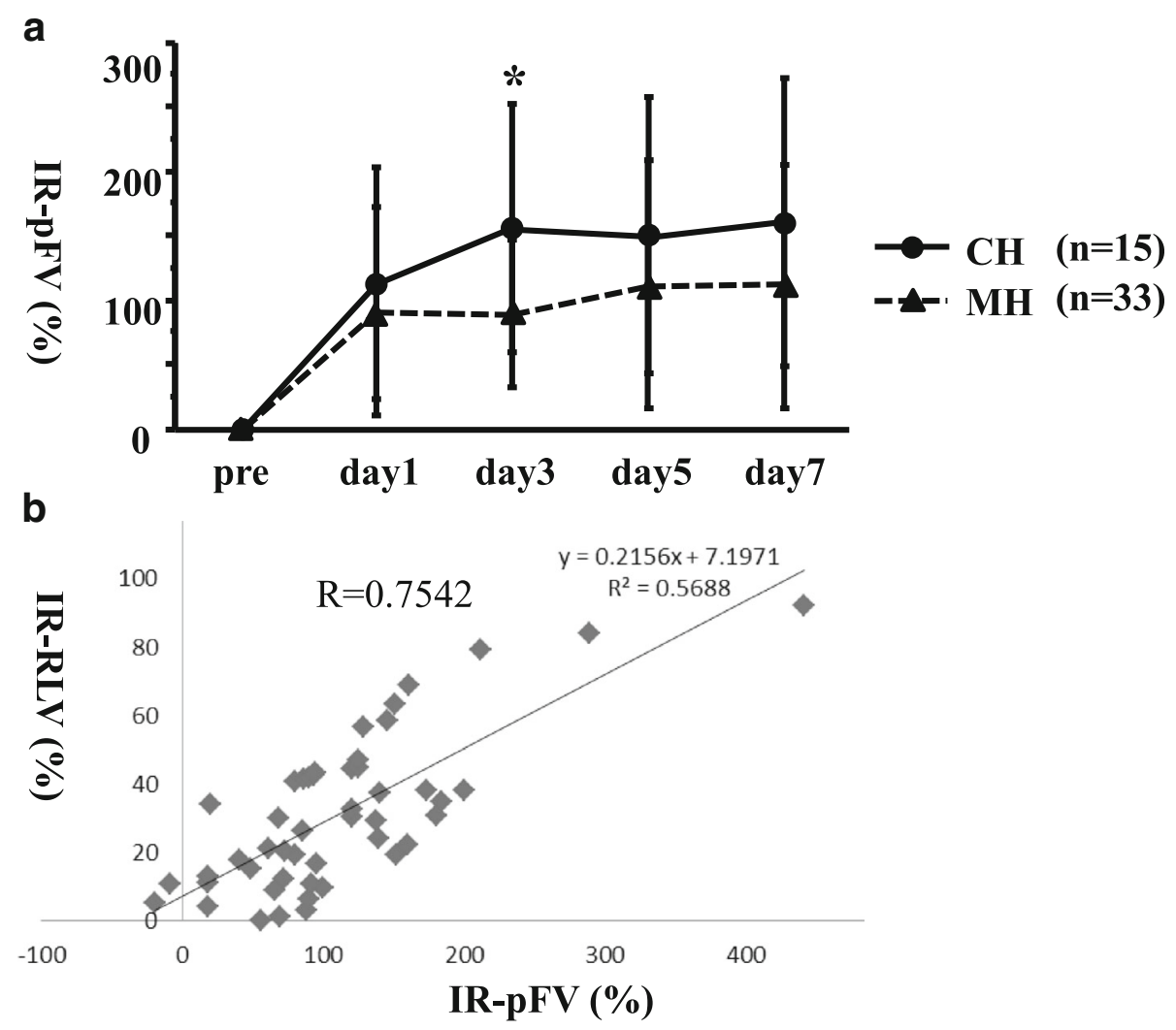

Fig. 2 a IR-pFV by US after PTPE. In the CH group, the IR-pFV continued to increase through day 1 until day 3. After day 3, the IR-pFV generally remained unchanged until day 7. The IR-pFV generally remained unchanged after day 1 in the MH group. ${ }^{*} P<0.01$. $\mathbf{b}$ Correlation between the IR-pFV at the non-embolized lobe by US on day 3 and the IR-RLV. The correlation coefficient was 0.7542 
Mars et al. [17] reported that urokinase-type plasminogen activator was immediately increased after partial hepatectomy. Urokinase-type plasminogen activator is induced by shear stress caused by increased blood flow [18] and activates hepatocyte growth factor [19]. Furthermore, nitric oxide (NO) is also induced by shear stress [20]. NO is produced by cytokine-inducible NO synthase (iNOS) and endothelial NO synthase (eNOS). Regeneration was inhibited after partial hepatectomy in mice with iNOS or eNOS inhibition [21,22]. Therefore, shear stress and blood flow might influence hepatic regeneration.

Recently, it was reported that the mechanisms of hepatic hypertrophy differ between post-PTPE and posthepatectomy [23, 24]. Some favorable and unfavorable factors have been identified for hepatic hypertrophy after PTPE, such as age, sex, body mass index, nutrition status, previous chemotherapy, and diabetes mellitus $[14,25]$. Chronic liver disease and cirrhosis are unfavorable factors for hypertrophy [3]. In addition, the presence of major portal hypertension and portosystemic shunts are unfavorable factors for hypertrophy [3, 26]. Our univariate analysis also demonstrated that PVP after PTPE and pathological liver fibrosis were significant favorable factors for hepatic hypertrophy after PTPE. In general, portal pressure will increase after PVE. Chen et al. [27] reported that patients with PVP below 16 $\mathrm{cmH}_{2} \mathrm{O}$ had a lower incidence of PHLF and patients with PVP of $20 \mathrm{cmH}_{2} \mathrm{O}$ or above showed lower incidence of grade $\mathrm{B}$ or $\mathrm{C}$ PHLF. It was reported that the 90-day mortality was associated with PVP greater than $21 \mathrm{mmHg}$ by Allard et al. [28]. Modulation of PVP may be important for better outcome.

Mihara et al. [29] reported that the ICG plasma clearance rate was a significant predictive factor for hypertrophy after PTPE. Kageyama et al. [30] reported that ICGR15 $>20 \%$ and T-bil $>1.5 \mathrm{mg} / \mathrm{dL}$ were unfavorable factors for hypertrophy after PTPE. These previous findings are consistent with our results.

The frequency of recanalization after PTPE ranges between 7.1 and $33 \%$ [31, 32]. In this study, the recanalization rate was $17.2 \%$. However, no cases exhibited recanalization at second or first portal branches. Some reports demonstrate that recanalization is a significant risk factor for poor hypertrophy [32, 33] possibly because pFV might be reduced at the non-embolized lobe in recanalized patients. Thus, we excluded recanalized patients.

Goto et al. [34] reported that an increase in the portal blood flow velocity after PTPE on day 1 correlated with the hypertrophy rate. Our univariate and multivariate analyses revealed that the pFV on day 3 highly correlated with increased hypertrophy after PTPE. Regarding the time course, the previous study demonstrated that the increase in the portal blood flow velocity after PTPE peaked on day 1 [34]. In contrast, we found that the increase in the portal blood flow after PTPE peaked on day 3 in the $\mathrm{CH}$ group and day 1 in the $\mathrm{MH}$ group. This discrepancy might be the key to good hypertrophy. Hayashi et al. [35] reported that the increase in the serum bile acid levels on day 3 after PTPE was a useful predictor of favorable hypertrophy. Using a portal vein ligation model in rats, Takamura et al. [24] demonstrated that the liver regeneration rate peaked between days 2 and 3 in the non-ligated lobe. Thus, we believe that the IR-pFV on day 3 after PTPE might be an important factor of hepatic hypertrophy after PTPE.

The limitation of this study is that the results may not really apply to the common population of PVE (liver metastases) because most patients were cirrhotic patients or cholestatic patients.

\section{Conclusions}

Preserved liver function, including ICGR15, and an increase in portal venous flow on day 3, i.e., portal venous flow shifted and added for the non-embolized lobe, are important for hepatic hypertrophy.

\section{Abbreviations \\ AUC: Area under the curve; $\mathrm{CH}$ : Considerable hypertrophy; $\mathrm{CT}$ : Computed tomography; eNOS: Endothelial NO synthase; ICGR15: Indocyanine green retention test at $15 \mathrm{~min}$; iNOS: Cytokine-inducible NO synthase; IR- $\mathrm{pFV}$ : Increase rate of portal venous flow volume; IR-RLV: Increase rate of remnant liver volume; LHL15: Receptor index: uptake ratio of the liver to the liver plus heart at $15 \mathrm{~min}$ of technetium $99 \mathrm{~m}$ diethylenetriaminepentaacetic acid galactosyl human serum albumin scintigraphy; $\mathrm{MH}$ : Minimal hypertrophy; NO: Nitric oxide; pFV: Portal venous flow volume; PHLF: Posthepatectomy liver failure; PTPE: percutaneous transhepatic portal embolization; PVE: Portal vein embolization; PVP: Portal venous pressure; RLV: Remnant liver volume; ROC: Receiver operating characteristics; T- bil: Total bilirubin; TIPE: Transileocolic portal embolization; US: Ultrasound sonography}

\section{Acknowledgments}

The authors would like to thank the staff of Gastroenterological Surgery I, Hokkaido University Graduate School of Medicine for their kind cooperation.

\section{Funding}

This study was not supported by any funding.

\section{Availability of data and materials}

The datasets generated and analyzed during the current study are available from the corresponding author on reasonable request.

\footnotetext{
Authors' contributions

SS and TK conceived the study concept and design, were involved with patient care and drafted the manuscript and literature review. HY, TO, KW, AN, TK, HK, and AT were involved with the formation of the study concept and design, patient care and drafting of the manuscript and literature review. DA and YS performed portal embolization on the patients and were contributors to the manuscript. All authors have read and approved the final version of the manuscript.
}

Ethics approval and consent to participate

All procedures in studies involving human participants were performed in accordance with the ethical standards of the Hokkaido University Hospital. 
This retrospective study was approved by the Hokkaido University Hospital Voluntary Clinical Study Committee with study number \#016-0091. Voluntary written consent was obtained from all patients.

\section{Consent for publication}

Not applicable. Individual identifying data were not included in this manuscript.

\section{Competing interests}

The authors declare that they have no competing interests.

\section{Publisher's Note}

Springer Nature remains neutral with regard to jurisdictional claims in published maps and institutional affiliations.

\section{Author details}

${ }^{1}$ Department of Gastroenterological Surgery I, Hokkaido University Graduate School of Medicine, Kita15-Nishi7, Kita-Ku, Sapporo, Hokkaido 060-8638, Japan. ${ }^{2}$ Department of Surgery, Sapporo Kousei Hospital, Kita3-Higashi8, Chuo-Ku, Sapporo, Hokkaido 060-0033, Japan. ${ }^{3}$ Department of Radiology, Hokkaido University Graduate School of Medicine, Kita15-Nishi7, Kita-Ku, Sapporo, Hokkaido 060-8638, Japan.

\section{Received: 4 April 2018 Accepted: 12 February 2019}

\section{Published online: 18 February 2019}

\section{References}

1. Spolverato G, Vitale A, Cucchetti A, Popescu I, Marques HP, Aldrighetti L, Gamblin TC, Maithel SK, Sandroussi C, Bauer TW, Shen F, Poultsides GA, Marsh JW, Pawlik TM. Can hepatic resection provide a long-term cure for patients with intrahepatic cholangiocarcinoma? Cancer. 2015; 121:3998-4006.

2. Shindoh J, Makuuchi M, Matsuyama Y, Mise Y, Arita J, Sakamoto Y, Hasegawa K, Kokudo N. Complete removal of the tumor-bearing portal territory decreases local tumor recurrence and improves disease-specific survival of patients with hepatocellular carcinoma. J Hepatol. 2016;64: 594-600.

3. Farges O, Belghiti J, Kianmanesh R, Regimbeau JM, Santoro R, Vilgrain V, Denys A, Sauvanet A. Portal vein embolization before right hepatectomy: prospective clinical trial. Ann Surg. 2003;237:208-17.

4. Shimamura T, Nakajima Y, Une Y, Namieno T, Ogasawara K, Yamashita K, Haneda T, Nakanishi K, Kimura J, Matsushita M, Sato N, Uchino J. Efficacy and safety of preoperative percutaneous transhepatic portal embolization with absolute ethanol: a clinical study. Surgery. 1997;121:135-41.

5. van Lienden KP, van den Esschert JW, de Graaf W, Bipat S, Lameris JS, van Gulik TM, van Delden OM. Portal vein embolization before liver resection: a systematic review. Cardiovasc Intervent Radiol. 2013;36:25-34.

6. Ribero D, Abdalla EK, Madoff DC, Donadon M, Loyer EM, Vauthey JN. Portal vein embolization before major hepatectomy and its effects on regeneration, resectability and outcome. Br J Surg. 2007;94:1386-94.

7. Leung U, Simpson AL, Araujo RL, Gönen M, McAuliffe C, Miga MI, Parada EP, Allen PJ, D'Angelica MI, Kingham TP, DeMatteo RP, Fong Y, Jarnagin WR. Remnant growth rate after portal vein embolization is a good early predictor of post-hepatectomy liver failure. J Am Coll Surg. 2014;219:620-30.

8. Kamiyama T, Nakanishi K, Yokoo H, Kamachi H, Tahara M, Yamashita K, Taniguchi M, Shimamura T, Matsushita M, Todo S. Perioperative management of hepatic resection toward zero mortality and morbidity: analysis of 793 consecutive cases in a single institution. J Am Coll Surg. 2010;211:443-9.

9. Sakuhara $Y$, Abo D, Hasegawa Y, Shimizu T, Kamiyama T, Hirano S, Fukumori D, Kawamura T, Ito YM, Tha KK, Shirato H, Terae S. Preoperative percutaneous transhepatic portal vein embolization with ethanol injection. AJR Am J Roentgenol. 2012;198:914-22.

10. Rous $P$, Larimore LD. Relation of the portal blood to liver maintenance: a demonstration of liver atrophy conditional on compensation. J Exp Med. 1920;31:609-32.

11. Makuuchi M, Thai BL, Takayasu K, Takayama T, Kosuge T, Gunvén P, Yamazaki S, Hasegawa H, Ozaki H. Preoperative portal embolization to increase safety of major hepatectomy for hilar bile duct carcinoma: a preliminary report. Surgery. 1990;107:521-7.
12. Kinoshita H, Sakai K, Hirohashi K, Igawa S, Yamasaki O, Kubo S. Preoperative portal vein embolization for hepatocellular carcinoma. World J Surg. 1986;10:803-8.

13. Azoulay D, Castaing D, Smail A, Adam R, Cailliez V, Laurent A, Lemoine A, Bismuth $H$. Resection of nonresectable liver metastases from colorectal cancer after percutaneous portal vein embolization. Ann Surg. 2000;231:480-6.

14. Kasai Y, Hatano E, Iguchi K, Seo S, Taura K, Yasuchika K, Mori A, Kaido T, Tanaka S, Shibata T, Uemoto S. Prediction of the remnant liver hypertrophyratio after preoperative portal vein embolization. Eur Surg Res. 2013:51:129-37.

15. Kodama Y, Shimizu T, Endo H, Miyamoto N, Miyasaka K. Complications of percutaneous transhepatic portal vein embolization. J Vasc Interv Radiol. 2002;13:1233-7.

16. Di Stefano DR, de Baere T, Denys A, Hakime A, Gorin G, Gillet M, Saric J, Trillaud H, Petit P, Bartoli JM, Elias D, Delpero JR. Preoperative percutaneous portal vein embolization: evaluation of adverse events in 188 patients. Radiology. 2005;234:625-30.

17. Mars WM, Liu ML, Kitson RP, Goldfarb RH, Gabauer MK, Michalopoulos GK. Immediate early detection of urokinase receptor after partial hepatectomy and its implications for initiation of liver regeneration. Hepatology. 1995;21:1695-701.

18. Sokabe T, Yamamoto K, Ohura N, Nakaztsuka H, Qin K, Obi S, Kamiya A, Ando J. Differential regulation of urokinase-type plasminogen activator expression by fluid shear stress in human coronary artery endothelial cells. Am J Physiol Heart Circ Physiol. 2004;287:H2027-34.

19. Mars WM, Zarnegar R, Michalopoulos GK. Activation of hepatocyte growth factor by the plasminogen activators UPA and tPA. Am J Pathol. 1993;143:949-58.

20. Hori N, Wiest R, Groszmann RJ. Enhanced release of nitric oxide in response to changes in flow and shear stress in the superior mesenteric arteries of portal hypertensive rats. Hepatology. 1998;28:1467-73.

21. Rai RM, Lee FY, Rosen A, Yang SQ, Lin HZ, Koteish A, Liew FY, Zaragoza C, Lowenstein C, Diehl AM. Impaired liver regeneration in inducible nitric oxide synthasedeficient mice. Proc Natl Acad Sci U S A. 1998;95:13829-34.

22. Mei $Y$, Thevananther $S$. Endothelial nitric oxide synthase is a key mediator of hepatocyte proliferation in response to partial hepatectomy in mice. Hepatology. 2011:54:1777-89.

23. Kogure K, Omata W, Kanzaki M, Zhang YQ, Yasuda H, Mine T, Kojima I. A single intraportal administration of follistatin accelerates liver regeneration in partially hepatectomized rats. Gastroenterology. 1995;108:1136-42.

24. Takamura K, Tsuchida K, Miyake H, Tashiro S, Sugino H. Activin and activin receptor expression changes in liver regeneration in rat. J Surg Res. 2005:126:3-11.

25. Yokoyama Y, Nagino M, Nimura Y. Mechanisms of hepatic regeneration following portal vein embolization and partial hepatectomy: a review. World J Surg. 2007;31:367-74

26. Bruix J, Castells A, Bosch J, Feu F, Fuster J, Garcia-Pagan JC, Visa J, Bru C, Rodés J. Surgical resection of hepatocellular carcinoma in cirrhotic patients: prognostic value of preoperative portal pressure. Gastroenterology. 1996; 111:1018-22.

27. Chen X, Zhai J, Cai X, Zhang Y, Wei L, Shi L, Wu D, Shen F, Lau WY, Wu M. Severity of portal hypertension and prediction of postoperative liver failure after liver resection in patients with child-Pugh grade a cirrhosis. Br J Surg. 2012;99:1701-10.

28. Allard MA, Adam R, Bucur PO, Termos S, Cunha AS, Bismuth H, Castaing D, Vibert E. Posthepatectomy portal vein pressure predicts liver failure and mortality after major liver resection on noncirrhotic liver. Ann Surg. 2013; 258:822-9.

29. Mihara K, Sugiura T, Okamura Y, Kanemoto H, Mizuno T, Moriguchi M, Aramaki T, Uesaka K. A predictive factor of insufficient liver regeneration after preoperative portal vein embolization. Eur Surg Res. 2013;51:118-28.

30. Kageyama Y, Kokudo T, Amikura K, Miyazaki Y, Takahashi A, Sakamoto H. Impaired liver function attenuates liver regeneration and hypertrophy after portal vein embolization. World J Hepatol. 2016;8:1200-4.

31. van Lienden KP, Hoekstra LT, Bennink RJ, van Gulik TM. Intrahepatic left to right portoportal venous collateral vascular formation in patients undergoing right portal vein ligation. Cardiovasc Intervent Radiol. 2013; 36:1572-9.

32. Malinowski M, Stary V, Lock JF, Schulz A, Jara M, Seehofer D, Gebauer B, Denecke T, Geisel D, Neuhaus P, Stockmann M. Factors influencing 
hypertrophy of the left lateral liver lobe after portal vein embolization. Langenbeck's Arch Surg. 2015;400:237-46.

33. Wilms C, Mueller L, Lenk C, Wittkugel O, Helmke K, Krupski-Berdien G, Rogiers $X$, Broering DC. Comparative study of portal vein embolization versus portal vein ligation for induction of hypertrophy of the future liver remnant using a mini-pig model. Ann Surg. 2008;247:825-34.

34. Goto Y, Nagino M, Nimura Y. Doppler estimation of portal blood flow after percutaneous transhepatic portal vein embolization. Ann Surg. 1998;228:209-13.

35. Hayashi H, Beppu T, Sugita H, Horino K, Komori H, Masuda T, Okabe H, Takamori H, Baba H. Increase in the serum bile acid level predicts the effective hypertrophy of the nonembolized hepatic lobe after right portal vein embolization. World J Surg. 2009;33:1933-40.

Ready to submit your research? Choose BMC and benefit from:

- fast, convenient online submission

- thorough peer review by experienced researchers in your field

- rapid publication on acceptance

- support for research data, including large and complex data types

- gold Open Access which fosters wider collaboration and increased citations

- maximum visibility for your research: over $100 \mathrm{M}$ website views per year

At BMC, research is always in progress.

Learn more biomedcentral.com/submissions 